\title{
Una hidra de siete cabezas. Peronismo en Córdoba, interconocimiento y voto hacia el fin del ciclo kirchnerista
}

A seven-headed hydra. Peronism, mutual knowledge and political alterity towards the end of the Kirchnerist cycle

\section{Julieta Quirós}

\section{(2) OpenEdition \\ Journals}

\section{Electronic version}

URL: http://journals.openedition.org/corpusarchivos/1595

DOI: 10.4000/corpusarchivos. 1595

ISSN: 1853-8037

\section{Publisher}

Diego Escolar

\section{Electronic reference}

Julieta Quirós, « Una hidra de siete cabezas. Peronismo en Córdoba, interconocimiento y voto hacia el fin del ciclo kirchnerista », Corpus [En línea], Vol 6, No 1 | 2016, Publicado el 01 julio 2016, consultado el 01 mayo 2019. URL : http://journals.openedition.org/corpusarchivos/1595; DOI : 10.4000/ corpusarchivos. 1595

\section{This text was automatically generated on 1 May 2019.}




\title{
Una hidra de siete cabezas. Peronismo en Córdoba, interconocimiento y voto hacia el fin del ciclo kirchnerista
}

\author{
A seven-headed hydra. Peronism, mutual knowledge and political alterity \\ towards the end of the Kirchnerist cycle
}

Julieta Quirós

Agradezco a Gerardo Quirós, Horacio Suárez, Ana Rosato y a mi estimado vecino Dardo, las críticas y comentarios al borrador. Agradezco también la calidad de la lectura y devolución de los evaluadores anónimos de Corpus, cuyas críticas y sugerencias me han permitido enriquecer esta versión final.

\section{Introducción: la derrota del kirchnerismo}

A Dante Lobos una sola pizca de alcohol de tanto en tanto le daba la saludable oportunidad de desanudar sentimientos y expresarlos con una franqueza locuaz. Esa tarde, como si sintiera que mi mirada le había pedido explicaciones, o como si supiera que sus explicaciones podían ser de mi interés, se acercó y me dijo: "Es que yo siempre lo seguí al César, sabés... Y mirá que soy radical eh", me aclaró, "pero yo siempre voy a estar con César...”. El Chango Murúa se levantó camino al salón y a su paso le dejó una palmada en la espalda; una manera de decirle, bueno Negro, ya va a pasar, lo que viniendo del Chango era decirle también, no es $p a^{\prime}$ tanto... Al fin y al cabo no era César el que había perdido, sino el candidato presidencial por el que había jugado -y por el que, en consecuencia, todos los que estábamos ahí habíamos trabajado durante esos meses electorales que terminaban ese mismo domingo 22 de noviembre de 2015, el día en que la historia de la democracia argentina tuvo su primera segunda vuelta de elección presidencial. 
"Hay que decirlo", lanzó César por fin, asumiendo la expectativa colectiva que lo circundaba, "esta es una provincia gorila..." Hizo una pausa y entendiendo que con eso no bastaba, amplió: "Con todo el dolor del alma tengo que decir que la misma gente que creció en estos años, que tuvo su casa, que consiguió laburo, que pudo jubilarse... Esa misma gente nuestra lo votó a Macri... Es así".

Mario Orieta, puntero profesional de César, completó el comentario con datos precisos: "Un 30\% de nuestra gente lo votó", dijo contundente, y la exactitud nos sorprendió a todos: cómo había llegado a esa cifra no lo sabíamos, pero a Orieta le encantaba tirar ese tipo de data, que en este caso seguramente resultaba de alguna relación que supo trazar entre los resultados de los cinco actos electorales -sí, cinco- que nos habían tenido trabajando esos meses: las elecciones municipales de mayo (que habían llevado a César Gordillo a ser elegido por tercera vez intendente de Mollar Viejo); las provinciales para gobernador y legisladores dos meses después (que en Mollar Viejo dieron por ganadora a la fórmula del peronismo provincial que César acompañó entonces); y las presidenciales, desdobladas en una serie inédita de tres: en agosto las elecciones llamadas PASO ( Primarias Abiertas, Simultáneas y Obligatorias), donde compitieron 15 precandidatos presidenciales; en octubre las generales, donde las fórmulas definitivas se estrecharon a 6 y dieron por ganador al candidato del oficialismo, el peronista Daniel Scioli, quien no llegó sin embargo a aventajar a la segunda fuerza por la diferencia reglamentariamente necesaria como para que la cosa terminara ahí, lo que nos llevó un mes después a votar en una segunda vuelta, cuyo resultado invirtió la relación de fuerzas de la anterior, consagrando como presidente al candidato de centroderecha Mauricio Macri y terminando, en contra de los pronósticos iniciales de un Scioli ganador, con un ciclo de 12 años de gobierno peronista conducido por el movimiento político conocido con el nombre de kirchnerismo. ${ }^{1}$

Estábamos en el bar de José Segundo, lugar que había oficiado de sede de encuentro y militancia de esa sesión continua y agotadora de gimnasia electoral que fue el año 2015; el bar quedaba a unos pocos metros de la plaza de Mollar Viejo, justo en diagonal a la escuela donde habíamos pasado esa jornada y donde todavía podían verse los últimos gendarmes y la directora con llave en mano, esperando para cerrar. Un par de horas más tarde, a unos 2 kilómetros de ahí para el lado de la sierra, mi vecino Dardo hacía su duelo en soledad. Subiendo con el coche por el camino oscuro y desparejo - había llovido mucho las últimas semanas-, pude ver el farol de la casa encendido. En el centro del patio, el último haz de luz que llegaba desde la galería me dejó adivinar su figura; sentado a la mesa, solo, quieto, la gorra de visera puesta, el ruido de los bichos y un paso más la oscuridad completa. Dardo, peronista de toda la vida y tres veces intendente de Mollar Viejo, a quien todavía le tocaba seguir de cerca los avatares de la política local porque el actual jefe comunal era ni más ni menos que su sobrino materno, el César, ese pibe que él había criado como a un hijo, me dijo estar desahuciado. Lo que más "le jodía" era que su propio partido tenía una "enorme responsabilidad": "iLo hicieron estos sinvergüenzas que enfrentaron a Córdoba con Nación todos estos años!”, despotricó, “¡Y decime para qué: si Córdoba tenía todo para ser kirchnerista! ¡Córdoba podía ser kirchnerista!”

Por los números que esa tarde le habían ido llegando a César por celular, nos habíamos dado una idea de cómo venía la mano en los municipios vecinos; pero solo íbamos a tener verdadera dimensión del fenómeno la mañana siguiente, al leer en los diarios que la fórmula presidencial de Mauricio Macri había ganado en la provincia de Córdoba con el $71,5 \%$ de los votos, lo que significaba que la cantidad de votos con que Macri superaba a su 
contrincante Scioli en Córdoba era mayor a la suma de las ventajas que le sacaba en todos los distritos del país. Si a nivel nacional Macri aventajaba a Scioli por la menuda cifra de casi 3 puntos (que lo consagraba presidente), en la provincia de Córdoba esa diferencia se multiplicaba a 44 puntos: la mayor del país. Le seguía en segundo lugar, y lejos, la ciudad de Buenos Aires (territorio político de Macri por excelencia) con 30 puntos de ventaja. En una palabra: el aporte de la provincia de Córdoba al resultado final había sido decisivo.

El día después y los que siguieron no faltó diario, radio y analista político que no hablara del fenómeno Córdoba. El "aplastante voto cordobés" a favor del macrismo no era otra cosa, coincidían especialistas, que el aplastante voto cordobés contra el kirchnerismo. " “ ¿Entenderá alguna vez el kirchnerismo lo que le costaron ocho años de ninguneo a esta provincia?", escribía un cronista en el emblemático La Voz del Interior. ${ }^{3}$ El entonces gobernador por tercer período y líder del peronismo cordobés, José Manuel De la Sota quien en los últimos años se había transformado en una de las figuras más prominentes del peronismo opositor a la presidenta Cristina F. de Kirchner- se relamía en el resultado; victorioso, vociferaba en los medios: "Los cordobeses dijeron 'Basta', los cordobeses votaron en contra del maltrato del gobierno nacional". ${ }^{4}$

La situación era públicamente conocida: si hubo una promesa en la que los tres principales candidatos a gobernador de Córdoba habían coincidido durante su campaña unos meses atrás, fue la de que garantizarían "mejorar la relación con Nación". Mejorar era un eufemismo: en todo caso la relación había que rehacerla, porque estaba rota. A los fines que nos ocupan en estas páginas, podemos decir que esa ruptura no es más que un caso ejemplar (en grado e intensidad) de un fenómeno más amplio que podríamos llamar la tensión basal -o si se quiere, para hacer uso de un arpegio hoy a la moda en el léxico político argentino, la grieta ${ }^{5}$ - entre un peronismo provincial de raíz conservadora (como el conducido por José Manuel De la Sota desde 1998 bajo la coalición de centroderecha Unión por Córdoba [UPC]) y un peronismo nacional que, como el kirchnerismo, se erigió sobre la alianza con sectores y consignas del progresismo, tanto peronista como no peronista, agrupados, desde 2003 en adelante, en la alianza electoral Frente para la Victoria (FPV). La "contingencia de los sucesos y recurrencia de las estructuras", al decir de Marshall Sahlins (1998), quiso que esa tensión estallara en el año 2008 -y no solo en Córdoba sino en otras provincias también-, con el llamado "conflicto del campo" o conflicto de "la 125", ${ }^{6}$ cuando Cristina F. de Kirchner cursaba su primer mandato como presidenta y sucesora del expresidente Néstor Kirchner. En Córdoba, el escenario se consuma como abierto enfrentamiento político en 2011, cuando J. M. De la Sota vuelve a la gobernación en un tercer mandado, ya como inflexible opositor al kirchnerismo. Para las elecciones legislativas de 2013, el delasotismo enarbola su propuesta partidaria con la bandera del "cordobesismo"; lejos de ser una exaltación localista, el lema interpelaba de lleno al resto de las provincias: "cordobesismo" era una forma de decir, Nosotros, el Interior $\mathrm{y}$, por tanto, la fórmula con que De la Sota se proyectaba como figura presidenciable de lo que muchos compañeros ya saboreaban, para 2015, como la posteridad del peronismo sin kirchnerismo.

Si hubo un actor damnificado en esta historia de enfrentamiento entre Córdoba y Nación que no fue otra cosa que la grieta dentro del propio peronismo-, ese actor fueron los intendentes cordobeses. Para ellos, a lo largo de por lo menos siete años, la gestión de las cuestiones más básicas de sus localidades se vio cada vez más condicionada y distorsionada por los traqueteos del conflicto político. Municipios como Mollar Viejo lo vivieron en carne propia: llegó un momento en que los funcionarios de los ministerios 
nacionales se acostumbraron a supeditar la concreción de convenios y obras al examen del prontuario de cada intendente: ¿Querés el CIC ${ }^{7}$ ? Veamos: ¿Sos compañero? Y el gobierno provincial hizo lo propio aceitando la palanca de retraso en los pagos de la coparticipación como forma de aleccionar a los intendentes sediciosos: ¿Necesitás cash? Veamos: ¿Firmaste la solicitada? ¿Dónde estuviste el 23 de junio de 2013? ¿Y por Buenos Aires cómo andamos? La peor parte le tocó a los intendentes peronistas: por las rutas del interior cordobés era vox populi que la gobernación recibía cordialmente a los intendentes de otros partidos, mientras ninguneaba a los peronistas que sabía o sospechaba en buenas migas con el gobierno nacional. Como me dijo una vez un exintendente de una pequeña ciudad del norte cordobés: "Que alguien me diga cómo carajo hacés para gobernar un municipio de estos con Provincia o con Nación jugándote en contra y yo me saco el sombrero".

Tabla № 1: La grieta dentro del peronismo, desde el caso cordobés

\begin{tabular}{|c|c|c|}
\hline & Provincia & Nación \\
\hline $\begin{array}{l}\text { Espacio o movimiento } \\
\text { político }\end{array}$ & delasotismo o sotismo & kirchnerismo \\
\hline Conductor & José Manuel De la Sota & $\begin{array}{l}\text { Néstor Kirchner } \\
\text { Cristina F. de } \\
\text { Kirchner }\end{array}$ \\
\hline Sello partidario & $\begin{array}{l}\text { Unión por Córdoba } \\
\text { (UPC) }\end{array}$ & $\begin{array}{l}\text { Frente para la } \\
\text { Victoria } \\
\text { (FPV) }\end{array}$ \\
\hline $\begin{array}{l}\text { Candidato } \\
\text { presidencial } 2015\end{array}$ & $\begin{array}{l}\text { J. M. De la Sota } \\
\text { (precandidato para las PASO por el Frente Unidos } \\
\text { por una Nueva Argentina, UNA) }\end{array}$ & Daniel Scioli \\
\hline
\end{tabular}

En este contexto, las elecciones presidenciales de 2015 eran, para todos, la esperada oportunidad para dar una vuelta de página. Los dos candidatos entre los que terminaría dirimiéndose el futuro del gobierno nacional supieron leer muy bien el significado y valor político de Córdoba: en agosto Daniel Scioli la eligió como lugar de lanzamiento y oficialización de su fórmula; una forma de decir: Soy kirchnerismo, pero voy a hacer las cosas distinto; mientras Mauricio Macri eligió Córdoba como lugar de cierre de su campaña para las generales de octubre; una forma de decir: Estoy acá porque soy Cambiemos. ${ }^{8}$

En términos generales, vale notar que esas elecciones, en su dinámica de tres series, ofrecieron una lógica expresiva peculiar. Podríamos ponerlo así: en la primera -las PASO -, cuando se presentaron 11 fuerzas partidarias con 15 precandidaturas, ${ }^{9}$ podías votar al partido o candidato que más te gustara, inclusive podías tener la suerte de tener un candidato que realmente te gustara, como también podías emitir cómodamente tu voto de protesta sufragando en blanco. Ese fue el momento de decir: el voto se acercó entonces al ideal cívico que Michel offerlé (2011) resume en la fórmula "un ciudadano, una opinión política". En la segunda serie, las generales de octubre, cuando se presentaron las 6 candidaturas efectivas, el acto del voto se fue acercando a una jugada en un tablero de 
relaciones: la mayoría de las personas se sintió compelida a desplazar el componente expresivo del voto de agosto en favor de algún tipo de apuesta o cálculo relacional. En la última serie, el ballotage, la antinomia Scioli o Macri pasó a expresar crudamente lo que estuvo en juego desde el principio: kirchnerismo o no-kirchnerismo. Muchos eligieron por uno $\mathrm{u}$ otro aun teniendo que taparse la nariz con los dedos al momento de depositar el sobre en la urna; el sistema les daba un consuelo: en agosto habían podido votar otra cosa y ese -y no este- era su verdadero voto (i.e: "Voto a Scioli, pero en las PASO voté al FIT [partido de izquierda]"; "Voto a Macri, pero en agosto y octubre mi voto fue a Margarita Stolbizer [candidata socialdemócrata]").

Podemos decir que el peronismo cordobés, entendido como estructura política, siguió esta misma lógica: si en las primarias de agosto y en las generales de octubre pudo darse el lujo de acumular capital político para un candidato propio, en el ballotage de noviembre su apuesta fue llamar al voto anti-K. No lo hizo declaradamente -entiéndase: Macri no es peronista y el principal socio de su coalición partidaria fue el radicalismo; ${ }^{10}$ el peronismo cordobés no podía oficialmente llamar a votar por eso-, pero sí en los hechos. Así, en vísperas a la segunda vuelta, en las localidades del interior pudimos ver a los representantes de Unión por Córdoba llevar y traer boletas de Cambiemos, y no faltaron figuras de referencia, como legisladores y presidentes del Partido Justicialista, que los días previos a la elección echaran a rodar en sus localidades un aviso que operó como abierta invitación: "Yo voto a Macri".

Debe notarse, sin embargo, que no todo el peronismo cordobés acompañó a sus conductores en esta jugada. Mucho antes de que a Daniel Scioli le fuera mal, hubo peronistas ligados al delasotismo que apostaron a poner un pie en ese espacio político que entre junio y noviembre supo esbozarse, y proyectarse a nivel nacional, con el nombre de "sciolismo". Peronistas cordobeses que vieron allí la posibilidad de vincularse, desde 2015 en adelante, a un gobierno nacional propiamente peronista. Y entonces el lector -el extranjero sobre todo- se preguntará: ¿pero cómo es esto?, ¿acaso "kirchnerismo" no es "peronismo"?, ¿y "peronismo cordobés" sería algo distinto a "peronismo"?, ¿y qué habría entonces del "sciolismo"?

“Peronismo?”, preguntó José Manuel De la Sota respondiendo a la pregunta “qué es el peronismo para usted" que le acababa de hacer un periodista, y seguidamente agregó: "Hoy hay muchos que se dicen peronistas; hay peronistasss (marcando la ese), pero no hay más peronismo". Una respuesta sobre la que acaso uno podría decir: no hay más peronismo del mismo modo que no lo había antes, si es que alguna vez lo hubo. Hace poco un político y polítologo argentino declaró en una entrevista periodística que el peronismo nunca había sido un partido: "El peronismo", dijo, "es una hidra de siete cabezas que se niegan a sí mismas pero que pertenecen al mismo tronco". ${ }^{11}$

Bien: este artículo trata de esa hidra. Con la particularidad de que propone seguirla en escala etnográfica, por intermedio de un puñado de situaciones vividas en la escena política de un conjunto de pueblos y pequeñas ciudades del interior cordobés. Para eso, nos valdremos de tres estrategias analíticas que propongo explicitar, a modo de metatexto (y también de advertencia al lector), en lo que sigue:

1. Las situaciones sociales que se analizan en este artículo resultan de una investigación etnográfica, actualmente en curso, sobre procesos políticos en comunas rurales de la provincia de Córdoba, y tienen por protagonistas a algunos de los peronistas díscolos que en las elecciones presidenciales de 2015 migraron fugazmente del peronismo cordobés conducido por José Manuel De la Sota a esa nueva versión del kirchnerismo que 
vislumbraron en la candidatura de Daniel Scioli. ${ }^{12}$ Es importante decir que, dentro del mapa del peronismo provincial, ese grupo de díscolos ha sido minoritario, tanto en número como en su influencia y visibilidad políticas. Si aquí propongo seguir algunos de sus movimientos es porque, en su condición de historias mínimas, sirven al doble objetivo que anima este artículo: a) interrogar etnográficamente al peronismo y los peronismos en su forma contemporánea, echando luz sobre la dinámica que adoptaron, en su seno y hacia el fin de la década kirchnerista, ciertas relaciones de alteridad -esto es: relaciones organizadas en torno a categorizaciones del tipo Otros/Nosotros-; b) interrogar etnográficamente la dinámica que asumen relaciones de representación política de diverso orden: las relaciones cara a cara de la política local, y las relaciones de representación, competencia e interdependencia entre distintos Estados y escalas de localidad -Municipio, Provincia, Nación- que hacen a nuestro sistema político en su funcionamiento concreto.

2. Este texto ha sido elaborado desde una perspectiva analítica que suelo llamar "antropología de la política vivida", expresión en la que el adjetivo "vivida" no comporta una pretensión conceptual sino más bien la apuesta por enfatizar y potenciar una práctica de conocimiento que define de manera crucial al quehacer antropológico: la posibilidad de abordar y analizar el mundo social en su condición de proceso vivo. Sin poder entrar de lleno en el significado e implicancias que contiene esta proposición (véase al respecto Quirós 2011, 2014a,), me limito a explicitar que ella se traduce en una serie de disposiciones etnográficas, de las cuales cabe aquí señalar por lo menos dos: en primer lugar, la puesta en práctica de una visión enérgicamente antiintelectualista de eso que en antropología solemos considerar el "punto de vista" o "perspectiva" de los actores, privilegiando, para ello, el seguimiento y análisis etnográficos de los microprocesos de acción e interacción a través de los cuales nuestros interlocutores de campo hacen -en el caso particular que nos ocupa- política. ${ }^{13}$ En segundo lugar, la seria consideración analítica, como pleno dato etnográfico, de toda aquella evidencia empírica que resulta de los múltiples sentidos cognoscitivos y formas de comunicación -no solo verbal sino también, y de modo fundamental, no verbal- que entran en juego en el trabajo de campo en tanto experiencia de participación del investigador en fragmentos de vida social, con y entre las experiencias de sus interlocutores (véase Favret-Saada 1990, Ingold 2000, Goldman 2006, Wacquant 2005).

3. Una de las implicancias que se desprenden de ambas disposiciones etnográficas atañe a la tercera estrategia analítica a explicitar aquí, la cual refiere a la propuesta textual contenida en este artículo. Ella guarda una doble apuesta: por un lado, la de propiciar y abogar, desde la antropología, por el reconocimiento de políticas de escritura que guarden fidelidad y adecuación epistémica con la naturaleza vivida de los medios de conocimiento implicados en la investigación etnográfica; por otro, la apuesta de que esas políticas no queden reservadas -como ocurre usualmente- a ámbitos intelectuales no académicos, sino que sean alojadas también en nuestras revistas especializadas (véase Quirós 2014a, 2014b). Para ello, suelo aclarar que interrogar la política en su dimensión vivida no equivale ni a aderezar nuestras descripciones con notas de color, ni a lanzarnos a experimentar nuestra veta literaria; se trata, al contrario, de entregarse al trabajoso ejercicio analítico de constituir en dato ciertos detalles cruciales de la experiencia etnográfica, para ponerlos al servicio de una economía lingüística específica: aquella necesaria y suficiente para relacionar contextos diversos y reponer la atmósfera -en el sentido sociológico que Marcel Mauss da al término- en que los procesos que estudiamos 
pueden ser analizados. Asimismo, interrogar la política vivida implica modelar y modular creativamente nuestro universo conceptual en pos de producir, como propone Mariza Peirano $(2008,2014)$, un encuentro genuinamente solidario y orgánico entre descripción y explicación, y entre etnografía y teoría antropológica.

La estructura narrativa de las páginas que siguen, el sustrato conceptual solo por momentos explicitado en que discurren sus preguntas y argumentos, y la licencia de dejar cabos sueltos en una descripción analítica que busca exponer las imbricaciones entre "hecho" y "valor" (Lenclud 2004), responden a estos criterios, y de modo general, a una práctica de antropología a la que este texto busca contribuir, con la convicción de que usar dinámicamente nuestros conceptos -usarlos operativamente como lentes que componen lo que Esteban Krotz (2012) llama "una determinada visión"- no significa volver nuestra disciplina menos rigurosa ni meramente descriptiva, sino que es, al contrario, fortalecer su agudeza comprensiva y explicativa, y sus posibilidades de intervención en los debates de la sociedad contemporánea.

Dicho esto, vuelvo entonces a nuestro escenario, Mollar Viejo.

\section{Una historia del peronismo desde el interior del interior}

Imaginate un grupo de pueblos y parajes ubicados al pie de una de las cadenas serranas de la provincia de Córdoba. Pueblitos desparramados a lo largo de un corredor de monte nativo que logró sobreponerse a las talas masivas de algarrobo y quebracho que abastecieron los sueños de progreso del ferrocarril en los siglos XIX y XX, y que desde entonces convive con los ejemplares de esa vegetación foránea que se estilaba implantar en los cascos urbanos y los puestos de estancia: el pino, el roble, el ciprés y el álamo. Cada pueblo tiene su plaza, su iglesia, su mercadito y su destacamento, y el que ya fue creciendo (y pasó de paraje a comuna, o de comuna a municipio) cuenta también con farmacia, estación de servicio, y quizás cajero automático. Históricamente, sus familias plebeyas se alimentaron a base de trabajo agrícola golondrina, economía familiar de subsistencia y la arquetípica recolección y venta de yuyos - hoy rebautizados, en un acto de valorización oficial, con el nombre de "hierbas aromáticas y medicinales". Sobre el duro trabajo del yuyero se edificó el pilar de la oligarquía local: las llamadas familias acopiadoras. La plusvalía fue históricamente brutal. Y aunque en la actualidad el esquema sigue vigente -el patrón yuyero conserva modalidades de paga y trabajo que a uno le hacen pensar que el primer peronismo no pasó por acá-, hoy hay más comercialización cuentapropista, y nuevos y mejor pagos oficios en el sector de servicios, propiciados por la expansión de la actividad turística, la cual en los últimos 15 años se ha constituido en una de las principales actividades económicas de la región.

En la última década otro fenómeno ha contribuido a este cuadro: la afluencia sostenida y creciente de gente oriunda de distintas ciudades del país (Buenos Aires, Gran Buenos Aires, Córdoba, Rosario, La Plata), que llega a afincarse en los interiores serranos en busca de modos de vida más simples, más despojados y próximos a la naturaleza. Junto al boom turístico, esta peculiar modalidad de migración interna -conocida entre los especialistas con el nombre de "neo-ruralismo"- está comportando profundas transformaciones en la fisonomía sociocultural serrana, como también en su economía: el antaño recolector de yuyos, hoy se volvió peón de albañil. 
En uno de estos pueblos, uno que apenas supera los 3000 habitantes, gobierna un intendente a quien hemos dado el pseudónimo de César, y quien oficiará de protagonista de estas páginas en la medida que forma parte de los jefes comunales que en ocasión de las presidenciales de 2015 se apartaron del peronismo delasotista para apostar a ese otro peronismo que se perfiló, a nivel nacional, con el nombre de sciolismo. Para analizar este proceso necesitamos primero hacer un repaso sucinto y parcial por la historia política de nuestro protagonista, quien en mayo de 2015 había sido electo por tercera vez intendente de Mollar Viejo.

Aunque desde sus inicios en la actividad política el espacio de pertenencia de César ha sido el peronismo cordobés, y aunque su principal referente y padrino político, A. Toñánez, ha sido y es una figura sumamente próxima al entorno del gobernador De la Sota, la manera en que César ha formado parte del delasotismo nunca fue, lo que se dice, convencional. En primer lugar, César no viene de una carrera política; tampoco es de esas personas que politizan cualquier asunto: el lenguaje político partidario le es más bien ajeno, como buen serrano habla poco - poco se sabe de su pensamiento, no es proclive a los posicionamientos- y cuando emite palabra lo hace en un léxico liso y llano, afín al vecinalismo que profesa como cuna e ideología política. Su auto-relato reza: él es un vecino al que un grupo de vecinos alentó en 2007 para construir un espacio que aspirara a la intendencia; ese espacio desafió fronteras partidarias: había peronistas, radicales e independientes; se fue sumando gente, ganaron la elección, las cosas fueron bien, se reeligieron en 2011, y ahí están y siguen siendo vecinos.

La saga guarda un detalle decisivo: inicialmente, en aquella primera elección de 2007, César buscó estructurar su espacio bajo el ala del peronismo cordobés, donde tenía varios contactos, sobre todo a través del tío Dardo, que había gobernado Mollar Viejo durante tres mandatos consecutivos por el peronismo. Ocurrió, sin embargo, que el Partido Justicialista no habilitó las elecciones internas que eran necesarias para que la fórmula de César fuera reconocida con su sello. Llegó el momento de cerrar las candidaturas y César y su lista no tenían partido por el cual presentarse. Qué hicieron: compitieron igual, tomando prestado el sello de una coalición provincial de corte vecinalista. Ganaron. No imaginaron cuánto esa falta primigenia de estructura partidaria se terminaría transformando, a la postre, en inagotable virtud: habían ganado solos, sin partido ni banca ni padrino; no le debían nada a nadie.

Esta condición de autonomía originaria, en buena medida involuntaria y fruto del componente "ciego", al decir de Norbert Elias (1989), del proceso social, será crucial para el futuro político de César. Porque si bien es cierto que, después de la victoria de esa primera elección, Toñánez viajó especialmente de Córdoba para felicitar a César y decirle "Te esperamos de brazos abiertos", y que poco tiempo después César se convertiría en uno más de los "intendentes de Unión por Córdoba", también es cierto que en esa integración logró conservar su cuota de independencia. En algún momento del año 2008, estas condiciones fueron al encuentro de otro tipo de contingencias sobre las que se mueve buena parte de la política real y a las que la tradición antropológica suele dar un nombre: las relaciones personales. La llegada a Mollar Viejo de uno de esos nuevos vecinos oriundos de Buenos Aires, a quien llamaremos B.B., le abrió inesperadamente a Cesar la posibilidad de crear un vínculo propio con Nación. B.B. se desempeñaba en un cargo de peso en el entonces Ministerio de Planificación; desde allí se dispuso a colaborar en todo lo que fuera necesario para que Mollar Viejo, ese apacible poblado serrano que él había elegido como refugio y lugar en el mundo, pudiera beneficiase de las políticas que ofrecía 
la cartera del gobierno nacional. La empatía con César fue inmediata y recíproca: el vínculo de confianza que fueron desarrollando le valió a César un enlace directo con oficinas ministeriales en Buenos Aires y Córdoba capital. Así llegaron a Mollar Viejo convenios para obras de agua, infraestructura, alumbrado público, y programas de trabajo, salud y desarrollo social. Un momento de gestión próspera al que le siguió la holgada reelección de César como intendente en 2011, su alineamiento electoral con el gobierno nacional de C. F. de Kirchner y su participación (aunque moderada y a su estilo) en las filas del Ente de Intendentes Unidos y Organizados (por el kirchnerismo). ${ }^{14}$

El primer palo en la rueda de esta travesía en la que todo parecía andar bien fue desatado por otra eventualidad: B.B. sufrió un repentino desplazamiento en el Ministerio de Planificación, lo que significó para César la pérdida de su referente e intermediario. Si hasta entonces la credencial $K$ de B.B. le había habilitado a César una cómoda articulación con diversos ministerios, ahora fue la ausencia de esa chapa la que pareció habilitar, de un día para el otro, una pregunta que muchos tenían ganas de formular: $Y$ vos, ¿quién sos? Digamos que lo que César tenía para contestar no era precisamente satisfactorio a los oídos de sus interlocutores $\mathrm{K}$, fundamentalmente de aquellos con oficina en Córdoba capital, para quienes el peronismo del que César provenía, el delasotismo, era un enemigo demasiado próximo. Pero estimo que eso no habría sido un problema insalvable, si no fuera porque precisamente en ese mismo momento Provincia y Nación -gobernador De la Sota y presidenta F. de Kirchner, peronismo cordobés y peronismo nacionalradicalizaban su enfrentamiento $\mathrm{y}$, con vísperas a las elecciones legislativas del año siguiente, cada cual se disponía a cerrar sus filas exigiendo lealtades y definiciones excluyentes. A cada intendente le dijeron: ¿De qué lado estás? En términos prácticos, para jefes comunales como César esto significó que cualquier acto de gestión empezara a estar sujeto a demostraciones y mediciones de compromiso -en su caso, con el autodenominado "proyecto nacional y popular". “ ¿No les basta con mirar el resultado de las elecciones de cada localidad?", se quejaba César. Y no bastaba: se necesitaban actos de militancia, iniciativa territorial y mediática, declaraciones públicas, dominio y uso profuso del lenguaje del "modelo". Nada más lejano a su estilo político. Los primeros síntomas de la crisis llegaron con la interrupción de algunas obras y, frente a eso, el margen decreciente de César para efectuar cualquier reclamo. El vínculo entre Mollar Viejo y Nación se había vuelto impersonal (Quirós 2014b).

De cara a las elecciones legislativas de 2013 el delasotismo salió a recuperar hijos perdidos. Toñánez se dio una vuelta por Mollar Viejo, se comió un asado en la casa de César y le ofreció garantías de respaldo económico. Para César fue como el reencuentro con un viejo amor que parece dispuesto a no preguntarte nada y simplemente en un abrazo te dice, Volvé. César retornó con el reanimo de quien vuelve a casa después de un largo viaje por un país donde se habla otro idioma y se comen otras comidas. En las legislativas de agosto de 2013 Unión por Córdoba volvía a ganar cómodamente en Mollar Viejo.

Dos años después, las presidenciales de 2015 abrían otro capítulo. Mientras, para César, apoyar la candidatura del delasotista Juan Schiaretti a la gobernación de Córdoba era algo que se caía de maduro - César consideraba al "Gringo" Schiaretti como su candidato natural: un tipo de vocación "realmente federal" que, a diferencia de su jefe y predecesor, miraba "más allá" de las grandes ciudades-, no le ocurría lo mismo con las pretensiones presidenciales del propio De la Sota. Sabía que jugar para De la Sota en las primarias (PASO) era trabajar en favor de la acumulación de capital político ajeno, para después 
tener que salir corriendo a alinearse detrás de alguno de los candidatos definitivos. Y en política no hay nada peor que llegar último a la fila. A la mayoría de los intendentes peronistas, sin embargo, no le quedó otra alternativa: por afinidad, lealtad y/o dependencia para con el jefe -el papi, como suelen bromear los entendidos de política por los pagos de Mollar viejo-, les fue imposible evadir el compromiso de acompañarlo. Naturalmente, solo los que conservaban algún grado de autonomía pudieron barajar otras jugadas.

En el caso de César fue nuevamente la contingencia de las relaciones personales la que le abrió una posibilidad impensada, la tarde de mayo en que tuvo la grata sorpresa de recibir el llamado de don Belisario Funes. Nacido y criado en un pueblo vecino a Mollar Viejo, Belisario Funes era un viejo conocido del tío Dardo. Hacía años que Funes no vivía en Córdoba, tantos como los que llevaba afincado en la provincia de Buenos Aires. Hasta donde César había tenido noticias, Funes siempre había trabajado para el peronismo duhaldista; y ahora -se enteraba- estaba oficiando de operador político del gobernador Daniel Scioli, quien por entonces formaba parte de los dos o tres precandidatos presidenciales que el kirchnerismo tenía en mente para las primarias de agosto. He aquí la razón de su llamado a César. ${ }^{15}$

La primera reunión fue en la casa natal de Funes, ubicada a unos pocos kilómetros de Mollar Viejo; le siguió otra que contó con la presencia de un representante del gabinete sciolista, venido directo desde La Plata. César salió entusiasmado y con una misión en la que vislumbró una cuña: sumar compañeros y armar una mesa de apoyo al candidato Scioli en la región. Luego vino la invitación a Buenos Aires a una reunión más amplia entre intendentes y el gabinete sciolista. Pocos días antes de consumarse la candidatura de Scioli como fórmula única del kirchnerismo para las PASO, César se dio el lujo de primerear, anticipando en un medio de prensa local: "En las elecciones provinciales acompañaremos al candidato Schiaretti, en las nacionales nuestro candidato es Daniel Scioli".

"Un cocoliche", ironizó Maricha al día siguiente con el diario en la mano, y su comentario expresaba una queja bien concreta: Maricha, empleada municipal y mano derecha de César, era la persona que tenía que lidiar todos los días con agentes del gobierno provincial y nacional para los asuntos de gestión más ordinarios, y estos, como bien sabía, no eran inmunes a las estrategias electorales de su jefe. "Decime, ¿ahora cómo les explico cuando me pregunten?", rezongaba. Ciertamente, con su declaración pública César anunciaba una jugada heterodoxa para ese momento; el propio medio local grabó la anomalía: "Pertenece a UPC pero va con Scioli", tituló la nota, cosa que fue bien recibida por César porque en cierto modo era el efecto buscado: posicionarse tempranamente, antes de que ser "sciolista" fuera una obviedad para cualquier peronista. Las tomas de posición en tiempos de acumulación originaria son verdaderas apuestas políticas, y como tales suelen ser debidamente retribuidas; ser sciolista antes de que el sciolismo fuera el peronismo ganador, fue la apuesta de César en 2015.

Mientras tanto, por los pagos serranos, los entendidos de la política ponían a circular sus explicaciones: "El viejo Funes vino a ponerle guita a los intendentes sotistas para que se den vuelta", se oía decir. Cosa que bien puede haber sido, pero para el caso debemos decir que A. Toñánez, principal emisario de De la Sota en la región, también vino a prometerles el oro y el moro con tal de que acompañaran al papi en las PASO. La pregunta es entonces: ¿Qué más había en esa jugada de César -a la que, dicho sea de paso, progresivamente se sumarían otros? ¿Por qué Scioli? 
Recordemos algo fundamental: para el ala progresista del kircherismo -que incluye a lo que se conoce como el kirchnerismo "duro y puro"-, la candidatura de Daniel Scioli, ese gobernador bonaerense que venía del peronismo de otros tiempos, ese gobernador forjado en la tradicional "estructura del PJ", fue aceptada de mala gana y como un mal necesario: una concesión que había que hacer para garantizar la continuidad del kirchnerismo por otros medios (recordemos más: los militantes $\mathrm{K}$ se preparaban para pasar el invierno y resistir "desde adentro" el "aluvión de derecha" que presagiaban). Por las mismas razones y con efectos inversos, podemos decir que Scioli representaba para muchos "intendentes del PJ" una suerte de profeta en camino a la tierra prometida. Como me dijo César una vez: "A mí me da la sensación de que ahora, con Scioli, el kirchnerimo se va a volver más peronista".

La apreciación, aunque dicha al pasar, no me pasó desapercibida. ¿Qué era un kirchnerismo "más peronista"? El izquierdista respondería: un kirchnerismo más derechoso. Mi hipótesis es que César respondería: un kirchnerismo más cordobés. Porque si hubo un problema entre Córdoba y kirchnerismo (subestimado en las lecturas de los especialistas de la política), es que el kirchnerismo-en-Córdoba ha sido demasiado cosmopolita; lo que quiere decir, demasiado e incorregiblemente porteño: porteño en sus representantes y emisarios, en su lenguaje y sus ceremonias, en sus modos y modales de hablar y explicitar. Así, por ejemplo, en vísperas a la campaña de las PASO de agosto, entre intendentes y legisladores del interior cordobés no pasaba desapercibido el hecho de que la primera candidata a diputada nacional de Córdoba por la coalición kirchnerista del Frente para la Victoria (FPV), fuera, además de dirigente de La Cámpora, ${ }^{16}$ una porteña afincada hacía unos pocos años en la provincia; como tampoco, que el primer candidato de la lista de concejales para la ciudad de Córdoba fuera Javier Barros, ese hombre de confianza de la ministra Alicia Kirchner originariamente enviado, desde Buenos Aires, para cumplir una doble e indisociable misión: desempeñarse como Secretario General provincial de la agrupación política Kolina ${ }^{17}$ y presidir el emblemático CDR (Centro de Referencia) del Ministerio de Desarrollo Social de la Nación con sede en Córdoba capital. CDR y Javier Barros eran el lugar y la persona por los que debía pasar todo intendente de Córdoba que tratara asuntos de incumbencia del Ministerio. "¿Te llevás mal con Barros? Cagaste”, era habitual escuchar, y iguarda el que osara puentearlo!

En los últimos años, el estilo de gestión de Barros había cimentado creciente malestar entre los intendentes, quienes se quejaban de que el CDR "bajaba" sus políticas "directamente", sin articular con los gobiernos municipales. Si miro de cerca la experiencia de Mollar Viejo, difícilmente podría caracterizar las intervenciones del Ministerio en esos términos. Victoria Mun, por ejemplo, la joven representante del CDR para todo el departamento al que pertenece Mollar Viejo, mantenía una comunicación fluida con las áreas y empleados del municipio, y los convocaba indeclinablemente a las reuniones de la "Mesa de Gestión Social" que coordinaba en la localidad. Es cierto que Maricha se enfurecía cuando la chica caía de Córdoba sin previo aviso; pero esas caídas de sopetón no eran distintas a la de otros agentes gubernamentales: Paren todo, llegué yo, le dice cada jurisdicción territorial a la que tiene por debajo. También es cierto que las actividades de Victoria Mun comportaban un claro afán por vincularse con las fuerzas vivas de la comunidad: sus pasadas por Mollar Viejo incluían visitas personalizadas a cooperativas, productores, agentes de salud y otros actores relevantes del lugar. Pero, nuevamente, esa cuota de puenteo tampoco estaba fuera de la normalidad de las relaciones entre Estados: en este caso, un ministerio nacional buscando realizar la aspiración de 
"llegar a cada argentino", preservando para ello sus políticas de las eventuales distorsiones a que podrían someterlas conflictos o internas locales.

En todo caso, el problema era que en todas y cada una de esas vinculaciones, los intendentes olían algo más: sabían que Victoria Mun no era solo una enviada ministerial, sino también la pieza fina de un engranaje político llamado kirchnerismo cordobés. Esta joven trabajadora social del Estado era también artífice del armado de una estructura política en sus ramificaciones capilares, estructura para la cual las localidades eran un universo virtualmente virgen y a conquistar. Dicho de otro modo: ese kirchnerismo configurado desde las grandes ciudades y sobre la base de agrupaciones políticas - La Cámpora, Kolina, Unidos y Organizados- necesitaba producir en los interiores de Córdoba eso que no tenía, o al menos no en la magnitud necesaria. Los políticos lo llaman territorio.

Veamos.

\section{3. "Llevar el voto": el interconocimiento como tecnología política}

"Al César sí que no le gana nadie", me decía una vez, con un tono de admiración que dejaba asomar su pizca de envidia, un militante peronista de un pueblo vecino a Mollar Viejo. En mayo de 2015 César había sido electo, con la abrumadora cifra del 71\% de los votos, intendente por tercera vez. "Y pensar que en la primera ganamos por ocho votos", recordaba el Chango Murúa, y Mario Orieta agregaba: "Ahí sí que había que saber pelear cada voto". Ocho años después de esa primera e histórica elección de 2007 las cosas eran muy distintas: ahora la victoria era certera; y fue tal vez por saber que, aun así, esta campaña necesitaba extraer de algún lado la dosis de épica que toda campaña necesita, que César abrió la primera reunión con su entorno de militantes ${ }^{18}$ con la siguiente consigna: "Esta vuelta", les dijo, "tenemos que ganar por mucho".

Las dos semanas previas a la elección municipal los vecinos de Mollar Viejo pudimos observar los típicos movimientos de tiempos electorales: escuchamos a los candidatos hablar en la radio de Paquita; fuimos invitados a participar de las distintas reuniones que cada uno organizó en distintos parajes; en la calle -y otro tanto en el Facebook- la gente fue siguiéndole el rastro a los movimientos y estimando adhesiones, erigiendo los números de una medición casera de eso que los técnicos electorales suelen llamar "intención de voto": si la reunión del César en barrio La Gruta convocó mucha gente o no tanta; si la fila de autos en el asado que organizó el Gustavo (otro candidato) era grande o chica; que cuántos kilos de chorizo compró el Gustavo para el asado y cuántos le sobraron; que cuántas vacas carneó el César para el cierre de campaña; si fue mucha o poca gente, y si fue más gente del Bajo que del Alto, y si era toda gente de Mollar Viejo o si el asado al final "se le llenó de gente de afuera y tendría que haber pedido DNI en la puerta como había dicho Dante Lobos"; también: si era cierto, como andaban diciendo, que el Marcelo Becerra, que siempre anduvo con el César, ahora "se había pasado" con el Gustavo; o si era cierto que la prima del Gustavo, a pesar de ser prima y cercana, le había dicho que la disculpara pero que ella el voto se lo daba al César.

Mientras las elecciones municipales suelen producir un involucramiento progresivamente generalizado de la comunidad, las provinciales y nacionales transcurren con una intensidad bastante menor; digamos que, a excepción del vecino politizado, no 
forman parte de los acontecimientos que mueven las fibras libidinales del común de la gente. Con toda la furia, a medida que se aproxima el día de la votación pueden escucharse algunos comentarios referidos al tema, sobre todo orientados a indagar, sondear o comunicar "con quién anda" (y por tanto "a quién llama a votar") cada candidato, dirigente o referente local:

“César, ¿qué hay que votar el domingo?", le pregunta un vecino al intendente en un encuentro casual.

"El Gustavo (ex candidato a intendente, opositor a César) anda llamando a votar por uno de los radicales", le comenta una mamá a otra en la puerta de la escuela mientras esperan a los chicos salir.

"Vino el César a traer el voto, le dejó varios a la mami", le comenta una chica de unos veintipico de años a su hermana.

"Llevar el voto" - es decir, la boleta de un partido- es una de las principales actividades de campaña electoral que realizan los candidatos y "su gente", la gente que trabaja o, como suele decirse, "pide el voto" para ellos. El comentario de arriba, de una hermana a otra, habla de una modalidad muy común: en una casa, los políticos dejan "varios votos" para que el jefe o la jefa de familia los distribuya entre los suyos. La práctica de llevar el voto está asociada a un pasado relativamente reciente, cuando la alfabetización no formaba parte de los saberes familiares de los adultos y mayores: el voto que dejaba el candidato se guardaba bien guardado porque era el mismo que uno iba a depositar en el sobre el día de la elección. Esta asociación late hasta el día de hoy: "A mí no me gusta que me anden trayendo el voto, yo sé leer, che”, se quejaba una vez mi vecina Framinia.

Sin embargo, llevar el voto es también una práctica esperada y considerada como algo que los políticos tienen que hacer. "Ni el voto vino a traerme", reclamaba otra vecina refiriéndose a César. "¿A quién hay que votar che? ¡Ni un voto me han traído esta vuelta!", se quejaba un muchacho como diciendo, ¡No hacen su trabajo! Los dos comentarios refieren menos a un problema informativo y más al tipo de interacciones implicadas en el acto de recibir el voto, que no es otra cosa que recibir la visita del candidato, expresión del valor que esas personas tienen para él. Al igual que en otras sociedades de interconocimiento (véase Rosato 2003, Palmeira 1992, 1996; Heredia 1996), en Mollar Viejo los candidatos y su gente no llevan el voto a cualquier casa: visitan a quienes conocen y con quienes tienen una relación previa. A lo sumo pueden ir a ver a aquellos que hoy el marketing electoral denomina "indecisos", pero nadie lleva el voto a una casa que sabe de otro signo político o adherente a otro candidato. $Y$ ese saber puede estar basado tanto en una constatación política -saber, por ejemplo, que tal familia es radical de toda la vida ("Pobrecitos, re peronistas son", me dijo una vez una militante radical de un pueblo vecino sobre una familia de la que le consulté por qué no visitábamos)-, como en conjeturas basadas en las "lealtades primordiales" (Palmeira 1996, p. 46) que se espera de las relaciones de parentesco y amistad: "No creo que don Carlos nos reciba, el yerno está en la lista de M. (candidato del otro partido)"; o: "Mari Palacios no va a votarnos, el hijo es muy amigo del chico Contreras, que está en la lista de M.".

El acto de llevar el voto es, como lo han mostrado los estudios arriba mencionados y otros, un momento de creación y reactualización de vínculos, como también de compromisos, los cuales pueden asumir la forma de intercambios de ese tipo de bienes que Michel Offerlé (2011, pp. 153 y ss) caracteriza como "particularistas y divisibles" -y que nuestra moral electoral condena; i.e: "Yo le ayudo con el voto, usted ayúdeme con la casa"; “¿Cuántas chapas necesita para terminar el techo?”-, como de esos que llama bienes "públicos indivisibles" -i.e: "Este año me comprometo a traer la luz al paraje, necesito 
que me ayude con el voto". Durante la campaña municipal de Mollar Viejo, como de otras que tuve oportunidad de acompañar en pueblos vecinos, los encuentros que semanalmente reunían a los candidatos y su entorno consistían básicamente en socializar la información sobre a quiénes se había visto y a quiénes falta ver:

- ¿A Irineo lo fue a ver alguien? - pregunta Dante Lobos a la mesa.

-Sí, yo lo vi -responde Maricha.

- ¿Le dejaste votos?

-Sí, le dejé.

- ¿Y a los Cepeda ya los hablaste?

-No, esta semana me llego a la casa.

La sucesión de interacciones como esta guardaba una división del trabajo implícita: cada persona va a ver a quien "tiene llegada". Lobos le preguntaba a Maricha por la familia Cepeda porque, como todos sabían ahí, era Maricha quien tenía relación -es decir, la mejor relación en términos de productividad política- con esa gente. Sin embargo, a lo largo de las reuniones el blanco principal de estas preguntas no eran los militantes, sino los candidatos:

- ¿Cesar lo viste a don Sosa ahí de La Cañada?

-No, Mario iba a verlo.

-Sí, Mario ya lo vio, pero tenés que llegarte vos.

- César ayer fui a verla a Silvina Cáceres, tenés que ir a darle una habladita vos.

En cada reunión César iba tomando nota de estas indicaciones; en los últimos días, con una indisimulable sensación de agobio, porque no daba abasto con las visitas. A candidatos de pueblos vecinos les pasaba lo mismo. La gente mayor se quejaba de que ahora los candidatos no pasaban por las casas como antes, y esto era en buena medida cierto: los pueblos habían crecido. Sin embargo, su temporalidad no parecía haber cambiado al mismo ritmo: era imposible para un candidato palmear a una casa y hablar cinco minutos en la puerta. En la costumbre serrana, llevar el voto es pasar al patio, sentarse a cruzar unas palabras. En el caso de parajes más lejanos, las casas que tienen relación con el candidato esperan que se quede a compartir una comida. Y sean más cortas o más largas las interacciones, todas deben respetar una regla tácita: en el ritmo serrano nunca se va directo al grano. En cualquier conversación, ir al punto demasiado rápido es considerado de mal gusto. Un vecino palmea a mi casa: lo recibo, nos saludamos, seguramente pasaremos un rato por varios temas de conversación y silencios, hasta que él trae el asunto por el que vino. En ese momento yo debo decodificar que ese es el asunto por el que vino, pero eso seguramente no es explicitado, y para llegar a él hubo necesariamente que pasar por otros, como una forma de reconocerse, ablandar el contexto de la interacción, habilitar un vínculo. Vale la pena decir que las reuniones de campaña que tuve oportunidad de acompañar seguían esta misma cadencia temporal; lejos de la celeridad que signa el ritmo político-electoral en contextos urbanos, en las reuniones de Mollar Viejo y pueblos vecinos cada cosa tenía su tiempo. Los encuentros en el bar de José Segundo, por ejemplo, duraban horas, y aun cuando todos los que estaban ahí estaban atrasados con las tareas pendientes, la reunión tenía más tiempos de los que uno consideraría "muertos" que tiempos de los que uno consideraría provechosos: el tiempo del chiste, el tiempo del silencio y de las anécdotas que se suceden, el tiempo de la picada y el ferné, un tiempo indeterminado y consagrado en que las personas sencillamente se dan las unas a las otras.

Ese mismo tiempo, estimo, es el que muchos vecinos esperan del candidato en sus visitas. Sin embargo, esto no es así en todas las elecciones. A diferencia de lo que ocurre en las 
municipales, en las provinciales y nacionales la práctica de llevar el voto tiende a asumir una dinámica más diligente y mediada. En primer lugar, no es necesariamente esperado que sea el dirigente quien lleve el voto o se dé "una llegadita", sino que bien puede hacerlo un emisario. Esta visita puede ser más corta y limitarse literalmente a "dejar el voto", acto que opera como una práctica propiamente informativa del tipo "el César vota a fulano", y cuya influencia o efecto coercitivo - ergo, hay que votar a fulano- dependerá de la relación que cada quien tenga con ese emisario o con el dirigente.

Tal vez cabe adelantarse a la visión autopercibida como republicana, que es capaz de ver en estas prácticas un "voto cautivo" o "voto compulsivo". Invito a ese ojo a prescindir por un momento de esa lectura para, en su lugar, observar de cerca la naturaleza de los hechos. La expectativa y disposición a que alguien -un político o referente político local como César, por ejemplo- te indique "a quién votar" nos habla de una modalidad específica de funcionamiento de la relación de representación política. Cuando de elecciones provinciales o nacionales se trata, la relación de representación y el acto de delegación son previos a la emisión del voto: delego en el César (o en el Gustavo) mi elección del futuro legislador, gobernador, inclusive presidente. Delegación que puede estar tan fundada en identificaciones partidarias como en la relación personal que se tiene con ese referente o dirigente en cuyo criterio y elección política se delega.

Es muy común que esa relación asuma y se exprese en una fórmula que a los cientistas sociales nos resulta una caja negra: el conocer al otro. "Al César lo conozco hace años"; "Con Gustavo nos conocemos de chiquitos". En pueblos como Mollar Viejo, "tener base política" es que te conozcan y que vos conozcas-a (fulano, mengano, zutano, "la gente") de algún lado, es decir, de alguna experiencia común: de la primaria, de la secundaria, del barrio, del bar, del club de fútbol, de la cooperativa de luz, del club de bochas, de la comisión de vecinos del paraje $\mathrm{X}$, de la cooperadora de la escuela, de la asociación de bomberos voluntarios. Es crucial notar que la fórmula lo conozco contiene una relación siempre recíproca: lo conozco quiere decir también, él me conoce a mí, y esto es una condición sine qua non para que un político sea seriamente considerando o, como ha señalado Ana Rosato (2003, pp. 75 y ss), un elemento decisivo del "capital político" de cada quien.

En las elecciones municipales de 2015 de un pueblo vecino a Mollar Viejo, el hijo menor de una acomodada familia radical se erigió súbita y vertiginosamente como figura candidateable, representando para el radicalismo local la promisoria oportunidad de recuperar la intendencia después de cuatro gobiernos consecutivos en manos del peronismo. Una vez formalizado como candidato, el joven inició una pujante campaña territorial, cosechando gran receptividad de parte de la comunidad. "Es un buen muchacho pero no tiene chances, pasó casi toda su vida en Córdoba, no conoce a nadie", repetían sus opositores en lo que acabó convirtiéndose en su principal caballito de batalla: el chico era del pueblo, pero los últimos quince años había vivido en Córdoba capital. Decir que "no conocía a nadie" era desacreditarlo en dos planos simultáneos: por un lado, exponer públicamente lo que es considerado una falta de cualidad y condición política $-\mathrm{y}$ es por eso que en alguna oportunidad pude ver a ciertos militantes del propio entorno del candidato ponerse nerviosos cuando el joven evidenciaba no conocer a alguien que, ellos estimaban, debía conocer-; por otro lado, es exponer una falla técnicamente categórica: no conocer a suficiente gente es no tener las redes de interconocimiento que necesitan ser movilizadas a la hora de pedir el voto. En este 
sentido, decir "no conoce a nadie" equivale a decir "no vale la pena votarlo porque no tiene posibilidades de ganar".

Sospecho que desde la antropología nos sigue costando dar un lugar analítico propio a la productividad política implicada en este tipo, o más bien, en esta intensidad de relación a la que podemos llamar de interconocimiento. Me refiero al hecho de que aun cuando nuestra tradición disciplinar clásica y contemporánea, como también corrientes fundamentales de la microsociología, cuentan con un rico y extenso recorrido en la materia, nos encontramos con dificultades para instalar, en los debates actuales e interdisciplinares, la importancia e implicancias de esta dimensión relacional en el funcionamiento efectivo de la política contemporánea. Repárese que interconocimiento no es lo mismo que (ni implica necesariamente un) vínculo de confianza personal: antes que referir a una relación de intimidad o de alta intensidad afectiva, el conocer-a (alguien) en los términos que lo he presentado arriba remite a un modo de relación que, valiéndonos de un término acuñado por la sociología de las redes, podemos llamar "relaciones débiles", o también, a una forma específica de "confianza" que proviene, tal como propone G. Simmel (1986), de un conocimiento difuso, general y más bien exterior del otro -la cual se diferencia de aquella otra forma de confianza que deriva de un conocimiento propiamente personal del otro "en sí". Ahora bien, en esa indeterminación o intensidad "débil" descansa la fortaleza de esas relaciones: ser conocidos o conocerse de alguna experiencia común remite a un nosotros no-dicho pero sabido, a una forma tácita de comunidad que, en el caso que me ocupa, está íntimamente vinculada a los contornos de la localidad. ${ }^{19}$

Hace algún tiempo, la invitación a participar de un coloquio interdisciplinario organizado por una universidad francesa bajo el título "La supervivencia y la dominación del peronismo en Argentina: ¿un enigma sociológico?”, me llevó a reexaminar material etnográfico proveniente de una investigación que desarrollé entre los años 2006 y 2010 en el marco de la elaboración de mi tesis doctoral, y en la cual analicé, entre otras experiencias, la dinámica de las relaciones políticas entre vecinos y referentes barriales más conocidos como "punteros"- del peronismo en el Gran Buenos Aires. Puesta a contraluz de mis investigaciones actuales en el interior cordobés, esa revisita me permitió identificar y dimensionar la subrepresentación que en mi propio análisis habían tenido las relaciones de interconocimiento, y en contraposición la sobrerrepresentación que adquirían relaciones interpersonales de mayor intensidad, sobre todo aquellas en las que yo podía identificar un vínculo de carácter afectivo-moral y/o contractual -intercambios y compromisos recíprocos- entre referentes y vecinos. Argumenté (Quirós 2014c) que este sesgo puede interpretarse como típico ejemplo y efecto de una práctica de conocimiento -enraizada en nuestras teorías políticas, tanto explícitas como implícitas, del sentido común y de las ciencias sociales- a la que llamé la "fascinación por el intercambio" o por "la dimensión transaccional" del comportamiento político que tiene por protagonistas a los sectores populares.$^{20}$ Sin embargo, hay algo más: pues cuando de peronismo se trata, este sesgo se torna particularmente prominente. En este sentido, la pregunta sobre el carácter "enigmático" expresada en el título del coloquio arriba referido, nos puede servir de llave para entrar de lleno en la cuestión, pues contiene una forma de interrogar que es también nuestra, y que se resume en lo que algunos analistas han caracterizado elocuentemente como el problema de "explicar el peronismo" (Neiburg 1998; Balbi 2009, 2007). Si acaso el peronismo fuera, como propuso recientemente uno de sus filósofos, una "obstinación" nacional (Feimann 2010), podríamos decir -recuperando la tesis de Federico Neiburg - que la histórica obstinación intelectual por "explicarlo" es 
parte de las prácticas epistemológicas y políticas que lo producen como tal. La disposición a abordar e interrogar al peronismo como "enigma" -condensada, y acaso inaugurada, por el emblemático “¿Qué es esto?” de Ezequiel Martínez Estrada (2005 [1956]) — nos ha jugado varias malas pasadas a las ciencias sociales. Una de ellas, señalada por Fernando Balbi (2009: 159), ha sido la repetición seriada de lo que el autor llama "soluciones analíticas totalizadoras", como aquellas implicadas en las clásicas explicaciones por el "carisma" o el "populismo". Me valgo de estos señalamientos para proponer que la "fascinación por el intercambio" puede ser caracterizada -y mejor interrogada y comprendida por tanto- como una versión contemporánea de este tipo de soluciones analíticas (versión que hace sistema, vale dejar indicado, con una de las principales lecturas) con que la ciencia social vernácula y foránea ha caracterizado las transformaciones atravesadas por la estructura partidaria del peronismo en los últimos 25 años, a saber: su mutación de partido históricamente organizado en torno al movimiento sindical a partido organizado sobre la capilaridad de redes territoriales de tipo clientelar (véase especialmente Levitsky 2005). ${ }^{21}$

Pondría mi argumento en estos términos: "explicar el peronismo" sigue siendo, para nativos y forasteros, desentrañar un (o varios) "enigma"(s) -el enigma de la representación (cómo produce votos), por ejemplo; el enigma de la movilización (cómo produce gente en la calle). Una de las formas de cumplir este cometido consiste en desnudar algún tipo de mecánica -i.e: la mecánica de la representación, la mecánica de la movilización. Mal que mal, el intercambio - consagrado en las teorías del clientelismo, tanto en sus versiones "economicistas" como en sus versiones "moralistas" y "contractuales" (cf. Vommaro y Quirós 2011) - comporta una mecánica que nos proporciona tranquilidad explicativa: "A le da a B entonces B le da a A". Desde luego que nuestra tarea es explicar cómo funcionan las cosas - las relaciones políticas, en este caso. El problema que se nos plantea, entonces, es propiamente epistemológico: ¿Por qué el intercambio ("Cuántas chapas necesita para terminar el techo") nos es transparente y suficiente en términos explicativos, mientras el interconocimiento ("Lo conozco"), nos resulta o bien una dimensión subsidiaria o bien una suerte de caja negra que virtualmente encierra algo distinto de lo que enuncia? ¿Qué cualidades y causalidades visibles guarda para nosotros el intercambio y qué atributos y conexiones invisibles nos representa el interconocimiento de modo tal que el primero aparezca analíticamente sobrerrepresentado en relación al segundo?

Me gustaría proponer que las relaciones de interconocimiento forman parte de esos hechos escurridizos pero decisivos de la dinámica de los procesos políticos, "hechos invisibles" - para valernos de una expresión malinowskiana- de la política, que la etnografía como modo de conocimiento está en condiciones de seguir e interrogar de manera privilegiada, y que una forma inicial, acaso provisoria, de hacerlo, es dar un lugar ontológico y epistemológico al interconocimiento en tanto tecnología política, es decir $-\mathrm{y}$ análogamente al intercambio- en tanto dimensión relacional que produce, configura y condiciona disposiciones para percibir, sentir, pensar y actuar políticamente de tal o cual manera.

En Mollar Viejo pude identificar esa tecnología operando en la producción de actos de delegación política. Y esto en por lo menos dos sentidos. Por un lado, así como podemos enunciar uno de los presupuestos rectores de la elección política a nivel local en términos de voto a quien conozco, decimos que las elecciones de mayor escala pueden movilizar este principio en relación transitiva: si César llama a votar por Toñánez es porque lo conoce; 
voto a quien mi conocido conoce; él conoce a quien yo no conozco ni me conoce a mí. Como he propuesto en otra parte, esta misma lógica puede explorarse para el caso de relaciones políticas cara a cara en contextos urbanos, por ejemplo, para las relaciones entre vecinos y referentes barriales en el Gran Buenos Aires (Quirós 2014c). Por otro lado, en estos actos de delegación se moviliza, unas veces más explícitamente, otras más implícitamente, una idea de bien común ligada a la comunidad y la localidad. Nociones que se integran en un supuesto compartido que sintetiza la siguiente expresión: "Es importante votar lo que vote el César, porque eso va a ser mejor para el pueblo".

Es común que los dirigentes "pidan el voto" por tal o cual candidato provincial o nacional invocando una pragmática del bien común delimitado por la localidad: para las provinciales de 2015, por ejemplo, César fue a las radios locales a dar su mensaje al pueblo de Mollar Viejo. Allí explicitó su apoyo al candidato delasotista Schiaretti y pidió a la comunidad que lo acompañara con el voto: Mollar Viejo, explicó, tenía "importantes proyectos en puerta con el gobierno provincial" y ese acompañamiento iba a garantizar "tener las puertas abiertas en la gobernación" para que los mismos prosperasen.

Si miramos el proceso electoral 2015 en su conjunto, vemos que las variaciones en los resultados de Mollar Viejo acompañan los movimientos políticos de César. En las provinciales de julio la fórmula del peronismo delasotista arrasa en Mollar Viejo con el 63\%; un mes después, para las primarias de agosto donde se presentan 15 precandidaturas presidenciales, el primer puesto pasa a ocuparlo el candidato kirchnerista de César, con el $46 \%$ de los votos - tengamos en cuenta que la fuerza partidaria de ese candidato, el FPV, sacó en la elección provincial celebrada un mes atrás solo el 13\%, es decir, que ahora ascendió 33 puntos, mientras la fuerza delasotista, esta vez encabezada por el propio De la Sota como precandidato presidencial, decreció 41 puntos. En octubre esta relación se mantiene con una variación significativa en favor del candidato Macri; un mes después, en el ballotage, el candidato presidencial de César asciende 10 puntos (alcanzando el 58\% de los votos), lo que significa que en Mollar viejo Daniel Scioli ganó por 15 puntos arriba del porcentaje que obtuvo a nivel departamental (donde perdió en favor de Macri) y 10 puntos por encima del que obtuvo en la media nacional.

Números que objetivan el territorio (de César), ese preciado lugar político - propongodonde no solo el intercambio, sino también el interconocimiento, producen votos. ${ }^{22}$

\section{4. "Muchachos acá tenemos que recibir a todos": el armado del sciolismo}

Si, como propuse más arriba, el kirchnerismo cordobés apostó a construir territorio valiéndose de acciones directas de sus emisarios (i.e: Victoria Mun) y prescindiendo de la dependencia de intendentes que no eran $(\mathrm{K})$ "puros", fue precisamente esta última posibilidad la que vinieron a abrir, a mediados de 2015, los operadores del sciolismo. Si intendentes peronistas como César vieron en la figura de un gobernador bonaerense como Scioli la posibilidad de peronizar el kirchnerismo, el sciolismo vio en esos intendentes la posibilidad de construirse territorialmente y desde los interiores, es decir, en un doble plano de diferenciación respecto de las estructuras típicamente $\mathrm{K}$-parlamento, grandes intendencias y agrupaciones políticas- con sede e inserción en las grandes ciudades. Quiero decir entonces que, por razones distintas pero concomitantes, sciolismo e intendentes necesitaban evitar Córdoba capital, y para eso se vinieron como anillo al dedo. 
Desde luego, la empresa no fue fácil. Al kirchnerimo preexistente no le fue fácil recibir de brazos abiertos a estos advenedizos de, como mínimo, dudosa procedencia. "Qué vivo, ahora que vamos de ganador resulta que todos están con nosotros...", protestaban los $\mathrm{K}$ de primera hora. "Sciolismo y kirchnerismo somos lo mismo, somos parte del proyecto nacional y popular", insistía porfiadamente en sus declaraciones mediáticas la primera candidata a diputada nacional de Córdoba por el FPV, mientras entre sus bases el problema no era otra cosa que esa pretensión de mismidad: "Resulta que ahora todos somos lo mismo: ¿Y los que bancamos los trapos cuando esto era el mismísimo desierto, qué?"

No faltaron actos de resistencia. Legisladores, agentes ministeriales e históricos “intendentes K" pretendieron que los recién llegados se subordinaran detrás de ellos respetando jurisdicciones territoriales. A César y sus compañeros vecinos les tocó de cerca con el viejo Cabroli, intendente K de Villa Carolina, ciudad cabecera de la región. Célebre por su estilo personalista, al viejo Cabroli le encantaba hacer ver ante sus jefes que movía a las intendencias menores en su zona; soñaba con erigirse en cacique $\mathrm{K}$ del norte cordobés. Faltando un mes para las PASO citó a César en su municipio: "Quiero invitarte a que te sumes", le propuso, a lo que César le habría respondido: "Sí, yo ya estoy sumado digamos...", lo que quería decir, Estoy adentro, pero no con vos. Cuentan que el viejo se puso como loco ante semejante desplante y es hasta el día de hoy que a César no lo quiere ver ni en figuritas. Cuando llegaron las primarias César se enteró de que Cabroli pretendía comandar la logística electoral partidaria - es decir, del FPV- de todo el departamento. Estábamos en el bar de José Segundo organizando las actividades para ese domingo cuando nos desayunamos de la movida, a raíz del "tema de las carpetas" de fiscalización:

-César, ¿las carpetas ya las tenés? - preguntó Mario Orieta en algún momento.

-No, me las traen el sábado -le respondió César.

- ¿No las tenemos que buscar nosotros mañana en Villa Carolina? -preguntó ahora

Carlos, un vecino que tenía buena relación con alguna gente del viejo Cabroli.

-Bueno, a mí supuestamente me las traen el sábado... ¿Vos por qué decís que hay que buscarlas allá? - preguntó César algo desconcertado.

-Ayer me dijo el Marco que el viejo estaba a cargo de todo el departamento, que tenía nuestras carpetas y que teníamos que buscarlas mañana -explicó Carlos algo incómodo.

-Bueno -lanzó el Chango Murúa en su tonada cordobesaza-: ¡parece que no se sabe quién tiene la manija acá!

En medio de las carcajadas, César enfiló para el patio discando el teclado de su celular. A simple vista parecía un tironeo de niños: estábamos hablando de las carpetas de cartulina que cada partido (el FPV en este caso) distribuye entre sus fiscales y que contienen el padrón de cada mesa de votación, una regla, una birome, y una planilla de control de votantes. El punto es que el significante "carpetas" guardaba otros significados. Primero, partidariamente, a las carpetas de fiscalización se asocian otros recursos destinados a la logística de la elección: vales de combustible, viandas para los fiscales, refrigerio para los locales partidarios. Quien recibe las carpetas recibe también estos recursos, de modo que decir "las carpetas" es hablar de la posibilidad -o no- de cada dirigente de gestionar esos recursos sin intermediaciones. Segundo, y más fundamental, cada acto de intermediación en relación a las carpetas es también un acto de expropiación de trabajo político. Si César recibe las carpetas "de Cabroli", al finalizar la jornada electoral esas carpetas deben volver - con las grillas de resultados completas por mesa de votación-al mismo Cabroli, quien a su vez las remitirá a su centro (jurisdicción o dirigente de 
referencia). Desde el punto de vista de ese centro, por tanto, esas carpetas cuentan todas como "mesas fiscalizadas por Cabroli" y, por tanto, suman al trabajo político de Cabroli, invisibilizando el que pudiera haber sido invertido por otros (intendentes o dirigentes menores). Así, el circuito que siguen las carpetas habla de quiénes son los políticos cuyo trabajo será socialmente reconocido y cuáles, en cambio, quedarán solapados, alimentando capital político ajeno.

César volvió del patio y confirmó que "efectivamente" el sábado le entregaban las carpetas de Mollar Viejo. Dante Lobos asintió con expresión de orgullo: se ponía contento cuando a su jefe -quien por la diferencia etaria que los separaba era también su pibe, su pollo- las cosas le iban bien. Esa misma noche, más tarde, César comentó que en la conversación telefónica Belisario Funes le había explicado que el problema de las carpetas venía a raíz de que Cabroli no aceptaba perder territorio públicamente. Cuentan las malas lenguas que dos meses después, en vísperas a las generales de octubre, el Cabroli estuvo horas reunido en Córdoba capital, peleando para que le devolvieran el control de las localidades de su zona. Parece que solo la charla con un dirigente de máximo peso pudo hacerlo entrar en razones: "Armando, tenés que entender que nosotros estamos sumando a los intendentes peronistas y ellos no se van a poner debajo de tu zapato. Y acá tenemos que recibir a todos..."

Cada jefe comunal organizaría el proceso electoral de su propia localidad, y en esto el sciolismo fue claro: estaba dispuesto a delegar en el peronismo impuro y heteróclito de los intendentes, actores y hacedores de territorios $-\mathrm{y}$ me pregunto si en licencias como esta no descansaba ese kirchnerismo más cordobés que leo en el kirchnerismo más peronista que César presagiaba. Lo único que el sciolismo les pidió a estos nuevos socios fue que, en sus localidades, "no se cortaran solos". Qué quería decir esto: que - "por favor", enfatizó Belisario Funes en una reunión- le hicieran un lugar a "los sectores" que ya venían trabajando con el kirchnerismo. ¿Quiénes eran? Los que aquí podríamos llamar (a los fines de diferenciarlos de su versión gubernamental y estatal) los $K$ de la sociedad. $\mathrm{Si}$, desde el Estado, funcionarios, legisladores, intendentes y dirigentes de agrupaciones kirchneristas pretendían subordinación de los advenedizos, los K de la sociedad -vecinos politizados, adherentes, y simpatizantes organizados en agrupaciones de baseesperaban, al contrario, inclusión por parte de estos intendentes súbitamente devenidos, en cada localidad, cara oficial del FPV.

En la región serrana a la que pertenece Mollar Viejo - al igual que en otras regiones serranas de la provincia- se da un fenómeno peculiar: esos $\mathrm{K}$ de la sociedad tienen una fisonomía propia, que coincide con los contornos de esa creciente oleada migratoria de origen urbano a la que referí algunas páginas atrás. "Los de afuera", los "llegados" o los "venidos", suele llamarnos -y me incluyo, pues soy una de ellos- el poblador nativo, que se autodenomina "nacido y criado"; en ámbitos de confianza, sin embargo, nos reserva un mote jocoso: los de afuera somos, básicamente, "jipis" - denominación que escribo con jota e i latina pues en el contexto que nos ocupa remite a una identidad distinta, si bien emparentada, a la del hippie. Como caractericé en otra oportunidad (Quirós 2014b), además de invertir el itinerario migratorio moderno, esta población comporta un claro perfil de clase: los jipis pertenecemos a esa unidad múltiple y porosa que es la clase media argentina $-\mathrm{y}$ así los hay de clase media cheta, media laburante, media metropolitana, suburbana, y provinciana. Entre otras implicancias, esa unidad asume una expresión política: "El porteño que se vino a afincar acá, todos kirchneristas, todos...", me decía una vez un intendente peronista en plena campaña electoral, como queriéndome decir, No 
tienen arreglo o No hay mucho que hacer ahí. Desde luego, no todos los nuevos vecinos somos kirchneristas de hecho (los anarco-ecologistas se indignarían ante semejante confusión y quienes se autoproclaman kirchneristas se horrorizarían por la injusticia y bien podrían impugnar: ¿Todos? ¡Ma’qué todos! ¡Cada jipi macrista tenés por acá!). Sin embargo, cultural y socialmente $-\mathrm{y}$ este es el punto crucial-, el grueso de los llegados forma parte de lo que recientemente un columnista del diario La Nación llamó, desdeñosamente, esa "progresía inespecífica" que ha nutrido al kirchnerismo como movimiento político-cultural de la Argentina reciente. ${ }^{23}$

En pueblos como Mollar Viejo puede encontrarse al jipi anarquista que no se presenta a votar porque "Cristina o Macri, son todo lo mismo", lo cual no quita que, en su vida cotidiana, comparta con su amigo kirchnerista una amplia variedad de gustos, criterios éticos, estéticos y políticos, frases hechas, formas de vestir, hablar y gesticular; esas cosas que decisivamente hacen del otro parte de un nosotros. El nacido y criado puede olfatear a la legua el perfume de esa sustancia común, como también sus implicancias políticas, y así sabiamente nos homogeniza "todos kirchneristas" - y en este sentido cabe reparar que, análogamente a lo que ocurrió en las esferas del Estado, en muchos rincones del interior cordobés el kirchnerismo también ha sido demasiado porteño.

El sciolismo captó que estos $\mathrm{K}$ de la sociedad eran (también) territorio: de allí el pedido de su inclusión a los intendentes. Desde luego, las posibilidades de concretar esa solicitud dependieron de la configuración previa de las relaciones en cada localidad. En Mollar Viejo el asunto fue particularmente fluido por dos razones convergentes que creo interesante mencionar aquí: por un lado, César tenía relación cordial con los llegados, quienes lo reconocían como un tipo accesible que había tenido, además, su fugaz pero no desdeñable "pasado K"; por otro, y más decisivamente, a diferencia de lo que había ocurrido en otros municipios, Mollar Viejo había podido celebrar sus elecciones municipales anticipada y separadamente de las elecciones provinciales y nacionales. Las consecuencias de este hecho fueron cruciales en la medida que habilitaron lo que, parafraseando a Pierre Bourdieu (2002), podríamos llamar el "intervalo de tiempo necesario" para que pertenencias políticas contrapuestas se tornen circunstancialmente secundarias o imperceptibles. Me explico:

Si César se plantó realizar sus elecciones con anterioridad a las provinciales, desobedeciendo abiertamente en este punto la voluntad de sus jefes sotistas -quienes trataron por todos los medios que los intendentes plegaran sus elecciones a las provinciales-, pagando, además, el costo político de esa insubordinación -entre otras cosas no recibiría un mango de UPC para su campaña municipal-, fue porque tenía muy claro que "provincializar" la elección local era partir su base política (vecinalista) en mil pedazos (partidarios). Desde luego que en Mollar Viejo este intendente era identificado con el signo de Unión por Córdoba. Pero en el mes de mayo, en el contexto de una elección exclusivamente municipal, el sello "UPC" significaba muy poco al lado del "César Gordillo, Intendente". En cambio, dos meses después, ese mismo sello estampado junto a la cara de los candidatos provinciales -Schiaretti gobernador y Toñanez legislador departamentalse transformaba en señal exclusiva y excluyente de delasotismo, lo que hubiera puesto en la vereda de enfrente de César no solo a sus votantes radicales, sino también a los peronistas $\mathrm{K}$. Y el vecinalismo que César representaba tenía esa particularidad: no solo aglutinaba distintas identidades partidarias, sino que fundamentalmente, y de modo más decisivo, era capaz de reunir a todos los peronismos posibles. 
Para las presidenciales de agosto de 2015 César llamó a todo ese territorio a votar por Daniel Scioli; lo cortés, sin embargo, no quitaba lo valiente: su apuesta al sciolismo no perturbaba los compromisos básicos con sus jefes delasotistas; así, en esas elecciones César aportaría, como lo había hecho siempre, sus fiscales generales y de mesa para Unión por Córdoba. En las dos primeras series de las presidenciales (que fueron las dos en las que UPC llevó candidato propio), por tanto, este intendente dispuso dos fiscales por mesa de votación, uno para el peronismo cordobés y otro para el peronismo kirchnerista desde luego, no faltaron expresiones satíricas al respecto:

"A ver señores, me prestan atención", nos ordenaba a viva voz el Chango Murúa, haciendo gestos de director de orquesta, la noche en que César nos había reunido en el bar de José Segundo a quienes íbamos a desempeñarnos ese domingo como (sus) fiscales; "Los kirchneristas", siguió el Chango, "se me ponen de este lado de la mesa por favor, y los nuestros (refiriéndose a los sotistas, entre quienes él se incluía), se me ponen de este otro lado. Ustedes (nos dijo ahora a los kirchneristas, entre los que él me incluía) llegaron demasiado temprano, porque los sotistas estábamos citados a las 8 y la gente de Scioli a las 9... Y bueno (agregó en medio de las risas generalizadas, impostando ahora un tono de resignación), también estuvieron los de Carrió (dirigente de otro partido)... Menos mal que el César los había citado a las 7 y media y se fueron a tiempo, porque si no acá sí que se armaba..." Mirándolo a César, remató irónico: “A vos quién te entiende..."

En lo que a la distribución de fiscales respecta, César dejó que cada quien siguiera sus inclinaciones y preferencias políticas: en términos generales, los fiscales del FPV fueron mayormente "llegados", mientras UPC fue fiscalizado exclusivamente por "nacidos y criados". En ocasión del ballotage César se jugó con un acto de militancia inusual: mandó a su gente a distribuir por las casas de Mollar Viejo una invitación al acto de cierre de campaña "Daniel Scioli Presidente", firmada por "César Gordillo, Intendente". La convocatoria, que representaba un fuerte posicionamiento y enérgico llamado al voto por el candidato, nos encontró a todos la noche previa al inicio de la veda electoral en la casa de don Artemio Figueras, presidente del Partido Justicialista de Mollar Viejo: nacidos y criados, jipis, sotistas, kirchneristas, radicales y no faltaron tampoco los independientes.

César armaba esos cocoliches como quien porfía en pegar piezas de porcelana con plastilina. Durante las campañas de ese 2015 pudimos verlo moverse como un malabarista en apuros, participando - por ejemplo- de un acto $\mathrm{K}$ y de un acto sotista en un mismo día con diferencia de unas pocas horas y unos pocos kilómetros. Y no es que la cosa le saliera redonda: era lanzar las bochas al aire para atajar algunas y que otras cayeran al piso; levantarlas y probar otra vez.

Me pregunto si su sciolismo no guardaba la ilusión de que esto fuera todavía posible a escala nacional: alguien que pudiera reunir, aunque más no fuera con la precariedad y circunstancialidad de un malabarista, a todos los peronismos posibles. Algo que en Córdoba hacía demasiado tiempo se había descocido.

La tarde de la derrota del candidato presidencial kirchnerista, ese 22 de noviembre de 2015, Dante Lobos lloraba porque seguía el razonamiento político que el poblador de toda localidad chica ha aprendido por experiencia propia: más vale llevarse bien con el que está arriba. César había jugado por el candidato equivocado, el perdedor, que en Mollar Viejo había resultado ganador con un caudal de votos que superaba por 10 puntos a la media nacional. Dante Lobos tenía miedo de que ahora al César -ese pibe que él, junto al tío Dardo, a Mario Orieta, a Maricha y al Chango Murúa, habían sabido labrar hasta convertir en político- estos números le jugaran una mala pasada. 
Vale notar que, dos meses más tarde, César ensayaba una lectura distinta y esperanzadora, que desplazaba el foco desde la relación Municipio-Nación hacia la relación de representación con la jurisdicción que mediaba en orden de jerarquía: Provincia. El nuevo gobernador de Córdoba, Juan Schiaretti, un tipo a quien César estimaba personalmente por su "vocación federal", y a quien había apoyado inobjetablemente en las elecciones provinciales de julio, iba a tener buena relación con el flamante presidente Macri. César confiaba en que los municipios cordobeses podrían, por fin, descansar en este acuerdo de paz y beneficiarse de sus compromisos recíprocos: Macri le debía mucho a ese delasotismo que había contribuido irrevocablemente al "aplastante voto cordobés"; y César, a través de su acompañamiento a Schiaretti, era también parte de ese peronismo.

En un mes tenía cita en Buenos Aires junto a otros intendentes por unas obras en curso con el Ministerio del Interior. Se preparaba optimista: salvo que alguien se ocupara de mirar los números chicos - cosa objetivamente improbable, razonaba César: decime quién va a ponerse a escudriñar los resultados de un pueblo minúsculo como Mollar Viejo en una provincia que aportó el mayor aluvión de votos macristas del país- las cosas tenían que andar bien. En 2016, el acento cordobés llevaba grabado el "71\%", una credencial amarilla con todas las de ganar.

\section{BIBLIOGRAPHY}

Abal Medina, P. (2016). Las formas políticas del trabajo. Revista Anfibia. URL: http:// www.revistaanfibia.com/ensayo/las-formas-politicas-del-trabajo

Abal Medina, P. (2015). Dilemas y desafíos del sindicalismo argentino. Las voces de dirigentes sindicales sobre la historia política reciente. Revista Trabajo y Sociedad, (24), 53-71.

Balbi, F. A. (2009). ¿Explicar "El peronismo”? Apuntes para un debate pendiente. Desarrollo Económico, 49 (193), 151-160.

Balbi, F. A. (2007). La dudosa magia del carisma. Explicaciones totalizadoras y perspectiva etnográfica en los estudios sobre el peronismo. Avá. Revista de Antropología, (11), 11-37.

Bezerra, M. O. (1999). Em nomes das 'bases'. Política, Favor e Dependencia Pessoal. Rio de Janeiro: Relume-Dumara.

Bourdieu, P. (1991 [1980]). El sentido práctico. Madrid: Taurus.

Chaves, C. de Alencar (1996). Eleições em Buritis: a pessoa política. En M. Palmeira y M. Goldman (Orgs.), Antropologia, voto e representação política, (pp. 128-164). Rio de Janeiro: Contra Capa.

Elias, N. (1989). El proceso de la civilización. Investigaciones sociogenéticas y psicogenéticas. México: Fondo de Cultura Económica.

Favret-Saada, J. (1990). Être Affecté. Gradhiva: Revue d'Histoire et d'Archives de l'Anthropologie, (8), 3-9. 
Feimann, J. P. (2010). Peronismo. Filosofía política de una persistencia argentina. Buenos Aires: Planeta.

Gaztañaga, J. (2013). Trabajo político: desde relaciones causales y la importancia de las acciones hacia una teoría etnográfica. Alteridades, (46), 111-126.

Goldman, M. (2006). Alteridade e experiencia: antropologia e teoría etnográfica. Etnográfica, 10 (1), 161-173.

Heredia, B. (1996). Política, família, comunidade. En M. Palmeira y M. Goldman (Orgs.), Antropologia, voto e representação política, (pp. 58-71). Rio de Janeiro: Contra Capa.

Ingold, T. (2000). The Perception of the Environment: Essays in livelihood, dwelling and skill. London: Routledge.

Krotz, E. (2012). ¿Qué se aprende cuando se estudia antropología? Conferencia Esther Hermitte. Estudios en Antropología Social, CAS-IDES, 2 (1), 3-14.

Lenclud, G. (2004 [1996]). Lo empírico y lo normativo en la etnografía. ¿Derivan las diferencias culturales de la descripción? En M. Boivin, A. Rosato y V. Arribas, Constructores de Otredad, (pp. 179-185). Buenos Aires: Antropofagia.

Levitsky, S. (2005). La transformación del justicialismo. Del partido sindical al partido clientelista, 1983-1999. Buenos Aires: Siglo XXI.

Martínez Estrada, E. (2005 [1956]). ¿Qué es esto? Catilinaria. Buenos Aires: Biblioteca Nacional y Ediciones Colihue.

Martucceli, D. y Svampa, M. (1997). La plaza vacía. Las transformaciones del peronismo. Buenos Aires: Losada.

Merklen, D. (2005). Pobres ciudadanos. Las clases populares en la era democrática (Argentina, 1983-2003). Buenos Aires: Gorla.

Neiburg, F. (1998). Los intelectuales y la invención del peronismo. Buenos Aires: Alianza.

Offerlé, M. (2011). Perímetros de lo político: contribuciones a una socio-historia de la política. Buenos Aires: Antropofagia.

Palmeira, M. (1992). Voto: Racionalidade ou Significado? Revista Brasileira de Ciencias Sociais, 7 (20).

Palmeira, M. (1996). Política, facções e voto. En M. Palmeira y M. Goldman (Orgs.), Antropologia, voto e representação política, (pp. 41-56). Rio de Janeiro: Contra Capa.

Peirano, M. (2008). Etnografia ou a teoría vivida. Revista Ponto Urbe (Online), (2).

Peirano, M. (2014). Etnografia não é método. Horizontes Antropológicos, 20 (42), 377-391.

Quirós, J. (2014a). Etnografiar mundos vívidos: desafíos de trabajo de campo, escritura y enseñanza en antropología. Publicar en Antropología y Ciencias Sociales, 17, 47-65.

Quirós, J. (2014b). Neoaluvión zoológico. Avatares políticos de una migración de clase. Cuadernos de Antropología Social, (39), 9-38.

Quirós, J. (2014c). Tramas micropolíticas: la dinámica del peronismo en un barrio del Gran Buenos Aires. Coloquio La survie et la domination du péronisme en Argentine: une énigme sociologique?, Université Paris 1, Panthéon-Sorbonne.

Quirós, J. (2011). El porqué de los que van. Peronistas y piqueteros en el Gran Buenos Aires (una antropología de la política vivida). Buenos Aires: Antropofagia. 
Rosato, A. (2003). Líderes y candidatos: las elecciones 'internas' en un partido político. En A. Rosato y F. Balbi (Eds.), Representaciones sociales y procesos políticos. Estudios de Antropología Social, (pp. 61-79). Buenos Aires: Antropofagia.

Simmel, G. (1986 [1939]). Sociología. Ensayos sobre las formas de socialización. Madrid: Ed. Alianza.

Varela, P. (2013). Del barrio a la fábrica: El proceso de repolitización fabril en la Argentina reciente. Amérique Latine Histoire et Mémoire. Les Cahiers ALHIM (En línea), (26), URL: http:// alhim.revues.org/4778

Vommaro, G. y Quirós, J. (2011). 'Usted vino por su propia decisión': repensar el clientelismo en clave etnográfica. Desacatos. Revista de Antropología Social, CIESAS, México, (36), 65-84.

Wacquant, L. (2005). Carnal Connections: On Embodiment, Apprenticeship, and Membership. Qualitative Sociology, 28 (4), 445-474.

\section{NOTES}

1. A excepción de personajes de alto conocimiento público, los nombres propios de quienes protagonizan estas páginas han sido cambiados. También se utilizan pseudónimos para los nombres de localidades y municipios.

2. La Nación, 24/11/2015, véase http://www.lanacion.com.ar/1848335-el-aplastante-votocordobes-contra-cristina

3. La Voz del Interior, 23/11/2015, véase http://www.lavoz.com.ar/politica/una-fuertemigracion-de-votos-con-destino-marcado-macri

4. La Voz del Interior, 22/11/2015, véase: http://www.lavoz.com.ar/politica/el-pueblo-decordoba-le-dijo-basta-un-ciclo-dijo-de-la-sota; y 24/11/2015, véase http://www.lavoz.com.ar/ politica/de-la-sota-sobre-el-fallo-de-la-corte-es-una-reparacion-historica

5. Para situar al lector extranjero: "la grieta", expresión originalmente acuñada, a modo de crítica política, por un periodista abiertamente opositor al gobierno kirchnerista, y luego popularizada en las arenas públicas para referir a la clave antinómica y antagónica (kirchnerismo/antikirchnerismo) que progresivamente fueron adoptando los debates públicos y pertenencias político-sociales en la Argentina reciente.

6. Nuevamente al lector extranjero: la escena política argentina del año 2008 giró en torno a lo que dio en conocerse como el "conflicto del campo", el cual enfrentó al sector agropecuario con el gobierno nacional de C. F. de Kirchner, a raíz del sistema de retenciones impositivas dispuesto -bajo la Resolución Nro. 125/2008 del Ministerio de Economía- a la exportación de trigo, maíz y soja. El conflicto desató un progresivo proceso de politización y movilización social que agregó y escindió a amplios y diversos sectores de la sociedad en dos posiciones que aprendimos a designar como "el gobierno" versus "el campo".

7. Centro de Integración Comunitaria (CIC), una de las políticas emblemáticas del Ministerio de Desarrollo Social de la Nación durante la administración kirchnerista.

8. Cambiemos, denominación de la coalición partidaria por la que Mauricio Macri compitió como candidato presidencial en las elecciones de 2015.

9. Una de las principales características y funciones de las PASO, en tanto instancia eleccionaria primaria estipulada por la ley electoral argentina, es que, al tratarse de elecciones simultáneas y obligatorias donde se definen las candidaturas efectivas que competirán en la elección general, cada partido o coalición partidaria puede presentar, y someter al voto general, más de una fórmula o precandidatura. De este modo, las PASO operan en la práctica como una elección interna dentro de cada partido, pero de carácter abierto. En esos casos - siempre que el partido 
haya alcanzado el piso mínimo del 1,5\% de votos previsto por la ley electoral-, la precandidatura ganadora deviene, automáticamente, candidatura oficial para la instancia de elección general.

10. Al lector extranjero: en Argentina hablar de "radicales", "radicalismo" o del partido Unión Cívica Radical (UCR), es hablar de la principal identidad política opositora al peronismo, y de la segunda fuerza del "bipartidismo" argentino a lo largo del siglo XX.

11. La Nación, 8/10/2015, véase http://www.lanacion.com.ar/1834894-dante-caputo-elperonismo-no-es-un-partido-es-una-ocasion-para-acceder-al-gobierno

12. La investigación referida se enmarca en el proyecto "Hacia una antropología comparada de la política vivida. Formas y experiencias de politización en comunas rurales" que llevo adelante desde el año 2013.

13. La mayor parte del material etnográfico analizado en estas páginas atañe a situaciones de acción e interacción que tuve oportunidad de acompañar y registrar en el marco de mi última campaña de trabajo de campo, desarrollada entre los meses de mayo y noviembre de 2015 . A lo largo de dicho período, delimitado por la realización de elecciones municipales, provinciales y nacionales, me dediqué a seguir, en su dimensión cotidiana y vivida, las actividades de diversos dirigentes políticos y sus colaboradores, concentrando mi labor en dos localidades, una de las cuales constituye, además, mi actual lugar de residencia. Vale señalar que, si bien dicha campaña fue desarrollada $-\mathrm{y}$ habilitada en esos términos por los protagonistas de los procesos acompañados - en calidad de etnógrafa - lo cual me permitió, entre otras cosas, poder circular por espacios partidarios de signos distintos-, mi condición concomitante de vecina constituye una identidad primaria e inescindible en lo que a mi inserción y producción de relaciones en campo respecta. A lo largo de estas páginas, el lector podrá apreciar que esa condición me torna, ineludiblemente, objeto de categorizaciones sociales y políticas propias del universo estudiado, y que estas operaciones son parte constitutiva de las condiciones en que se desarrolla mi investigación. Para un análisis más específico de estas cuestiones, véase Quirós $2014 \mathrm{~b}$.

14. Unidos y Organizados, sello de un espacio político de nivel nacional, constituido pocos meses después de la reelección de Cristina F. de Kirchner a la presidencia, en el cual se aglutinaron diversas fuerzas (movimientos sociales, organizaciones políticas y partidarias) del progresismo y el peronismo llamado " $\mathrm{K}$ ".

15. Recupero en este punto los análisis de Julieta Gaztañaga (2013) sobre el "trabajo político" de los profesionales de la política como el arte de "hacer relaciones".

16. Agrupación política kirchnerista. Véase nota siguiente.

17. La agrupación política Kolina (Corriente de Liberación Nacional) comparte con La Cámpora (por lo menos) un rasgo común: el de ser espacios originariamente constituidos de arriba hacia abajo, esto es, desde figuras y funcionarios del propio Estado nacional, con vistas a articular territorialmente la militancia kirchnerista y/o afín al kirchnerismo.

18. Cabe mencionar que este no es un término de uso corriente en el universo estudiado, donde más bien se habla de "la gente de" o "la gente que está con" tal dirigente, candidato o político.

19. Recupero aquí los análisis sobre las relaciones entre política y localidad que proponen Christine de Alencar Chaves (1996), Marcos Bezerra (1999) y Beatriz Heredia (1996) para el caso de municipios del interior del Brasil.

20. Para un desarrollo de esta caracterización, véase Quirós 2011.

21. Véase también Martuccelli y Svampa 1997. La mutación de la estructura partidaria del peronismo que la obra de Steven Levistsky sintetiza en la fórmula "de partido sindical a partido clientelista", se inscribe en -y es caracterizada en buena medida como respuesta o adaptación a - los procesos de desindustrialización y des-proletarización que signaron la Argentina de fines de los años 80 y década del 90 . Aun sin poder desenvolver aquí la cuestión en todos sus aspectos e implicancias, considero oportuno dejar indicada la afinidad analítica de esta lectura con la centralidad ganada por el "intercambio" en las preguntas y respuestas sobre la naturaleza y funcionamiento de la adhesión popular al peronismo en la Argentina postsalarial. Indico, 
asimismo, que esta centralidad - analítica, social y polític-- debe entenderse, también, a la luz de procesos más amplios, como el de la territorialización de la actividad económica y política de los sectores populares que diversos autores (véase especialmente Merklen 2005) han identificado y propuesto como clave interpretativa de las transformaciones sociales y políticas del período. Lo que este último autor propone denominar la "inscripción territorial" de los sectores populares, se ve condensado en un desplazamiento en el locus de la organización y producción de identidades políticas: antes era la fábrica, ahora el barrio. Trabajos recientes exploran las transformaciones e inversiones de este desplazamiento, a la luz de las reconfiguraciones en el mundo del trabajo de la última década (véase Abal Medina 2015, 2016; Varela 2013).

22. Dejo para otra oportunidad las implicancias que estos señalamientos comportan para los debates actuales sobre el voto electrónico y su presunta profilaxis relacional -la cual comporta un perfeccionamiento, al decir de M. Offerlé (2011), del simulacro colectivo del votante como individuo "des-socializado", despojado (ahora sí) de cualquier objeto (i.e: la boleta) capaz de ligarlo a algo/alguien exterior y anterior al acto de emisión del voto. Solo él y la máquina. Solo él, su conciencia y su dedo. La sucesión de gafes que un observador puede apreciar a lo largo de una jornada electoral celebrada en lugares como Mollar Viejo, donde los procedimientos del buen votar no gozan de amplia familiaridad o naturalidad (las sutiles pero generalizadas dudas corporales con relación a cada paso a seguir, la extrañeza hacia órdenes como el alfabético), permiten al observador tomar dimensión del montón de técnicas electivas que, como historiza brillantemente Offerlé, fue necesario aprender e incorporar para que la simulación de la dessocialización fuera naturalizada, olvidándonos de su impostación, como puede ocurrir con las maneras de mesa, el nudo de la corbata, o cualquier otra etiqueta social de ese tipo.

23. Véase: http://www.lanacion.com.ar/1870898-los-tres-dilemas-que-acosan-al-presidente, $14 / 02 / 2016$.

\section{ABSTRACTS}

This article explores the contemporary forms of Peronism in Argentina, as well as the nature and functioning of several representation and delegation relations that give form to our political party system, by drawing on an ethnographic research conducted during local, regional and national election processes carried out in 2015. With an anthropological live-politics approach, it examines some micro-political processes occurred among a set of rural villages of the Province of Córdoba; it specifically follows some of the unruly partisans that shifted from the traditional peronismo cordobés to a new established peronismo kirchnerista, grouped together under the presidential candidacy of Daniel Scioli. In doing so, this article seeks to acknowledge the contributions of Anthropology to the understanding of the dynamics of otherness, shaped in the core of Peronism at the end of the Kirchnerist age; also, to understand the dynamics that build up the representative democratic system in its actual functioning: mutual knowledge relations as political technology of territory; logics of representation, competition and interdependence that mark the relations between capital and interior, among States-Municipality, Province, Nation-, and their different degrees of locality.

En base a un análisis etnográficamente situado de procesos electorales locales, provinciales y nacionales que signaron la Argentina de 2015, este artículo busca contribuir a comprender el peronismo y los peronismos en su forma contemporánea, como también la naturaleza y 
funcionamiento de diversas relaciones de representación y delegación que hacen a nuestro sistema político partidario. Valiéndonos de la perspectiva de una antropología de la política vivida, examinamos para ello una serie de experiencias y microprocesos políticos que tienen por escenario a un conjunto de pueblos y pequeñas ciudades del interior de la provincia de Córdoba, y por protagonistas a algunos de los peronistas díscolos que en las elecciones presidenciales de 2015 migraron fugazmente del peronismo cordobés, conducido por el entonces gobernador José Manuel De la Sota, hacia el kirchnerismo encolumnado tras la candidatura presidencial de Daniel Scioli. A través de este análisis, buscamos explorar los aportes que la antropología puede hacer a la comprensión de la dinámica de ciertas relaciones de alteridad configuradas en el seno del peronismo hacia el final de la década kirchnerista, como también la dinámica que asumen diversas relaciones políticas que hacen al sistema de democracia representativa en su funcionamiento concreto: las relaciones de interconocimiento como tecnología política del territorio; las lógicas de representación, competencia e interdependencia que signan las relaciones entre centros e interiores, y entre Estados - Municipio, Provincia, Nación- en sus distintas escalas de localidad.

\section{INDEX}

Keywords: Peronism, mutual knowledge, vote, ethnography, Córdoba

Palabras claves: peronismo, interconocimiento, voto, etnografía, Córdoba

\section{AUTHOR}

\section{JULIETA QUIRÓS}

Consejo Nacional de Investigaciones Científicas y Técnicas, Instituto de Antropología de Córdoba, Universidad Nacional de Córdoba, Argentina.

Correo electrónico: juquiros@hotmail.com 